\title{
Induction of adiponectin gene expression in human myotubes by an adiponectin-containing HEK293 cell culture supernatant
}

\author{
H. Staiger, C. Kausch, A. Guirguis, M. Weisser, E. Maerker, M. Stumvoll, R. Lammers, F. Machicao, \\ H.-U. Häring \\ Department of Endocrinology, Metabolism, and Pathobiochemistry, Medical Clinic Tübingen, Eberhard-Karls-University, \\ Tübingen, Germany
}

\begin{abstract}
Aims/hypothesis. Adiponectin, an adipocytokine known to be down-regulated in obesity-linked disorders, is considered to be a potential key mediator of insulin sensitivity. In this study, we asked whether adiponectin is able to regulate ten selected genes possibly associated with insulin sensitivity in human skeletal muscle cells.

Methods. To this end, we treated in vitro differentiated human myotubes with the culture supernatant of HEK293 cells stably transfected with human recombinant adiponectin and assessed gene expression by RTPCR. Intracellular adiponectin protein was quantified by radioimmunoassay and visualized by Western blotting. Results. In contrast to the control supernatant, the adiponectin-containing supernatant consistently induced
\end{abstract}

expression of adiponectin mRNA in human myotubes from eight different donors (mean increase: 90-fold over control; $n=8, p<0.001)$. This increase in mRNA was paralleled by a rise in intracellular adiponectin protein (mean increase: 8.3-fold over control; $n=4$, $p<0.05$ ). Expression of the other nine candidate genes was not altered. In human skin fibroblasts and HepG2 cells, the adiponectin-enriched supernatant did not induce relevant amounts of adiponectin mRNA.

Conclusions/interpretation. In conclusion, we show here that adiponectin gene expression is specifically inducible in skeletal muscle cells. [Diabetologia (2003) 46:956-960]

Keywords Adiponectin, adipocytokines, insulin sensitivity, skeletal muscle cells.
Obesity becomes increasingly evident in Western industrialized countries due to malnutrition and a sedentary lifestyle combined with a genetic predisposition. It is a major health problem because of its close association with modern civilization diseases, like insulin resistance, Type 2 diabetes, hypertension, and athero-

Received: 31 October 2002 / Revised: 13 February 2003

Published online: 21 June 2003

C) Springer-Verlag 2003

Corresponding author: H.-U. Häring, Department of Internal Medicine IV, Medical Clinic Tübingen, Otfried-Müller-Str. 10, 72076 Tübingen, Germany

E-mail: hans-ulrich.haering@med.uni-tuebingen.de

Abbreviations: FAT, fatty acid transporter; FATP, fatty acid transport protein; HA, haemagglutinin; HEK, human embryonic kidney; MFABP, muscle fatty acid binding protein; PGC, peroxisome proliferator-activated receptor- $\gamma$ coactivator; PPAR, peroxisome proliferator-activated receptor; UCP, uncoupling protein. sclerosis. In this context, hypertrophic adipose tissue is thought to influence other peripheral tissues (muscle, liver, pancreas) by dysregulated secretion of fatty acids and a limited number of hormone-like polypeptides, now better known as adipocytokines. Among these, leptin and adiponectin were recently shown to have insulin-sensitizing activities [1].

Adiponectin is a protein with a molecular weight of about 30,000 $\mathrm{M}_{\mathrm{r}}$ which is exclusively and abundantly produced by adipocytes and circulates at high concentrations in the bloodstream $(0.01 \%$ of total plasma protein). Its plasma concentrations are reported to be decreased in obesity, insulin resistance, hyperinsulinaemia, and coronary heart disease (for review, see [2]). Insights into its molecular function were derived from studies in mice. Adiponectin enhances the insulin-dependent suppression of hepatic gluconeogenesis, thereby lowering plasma glucose concentrations [3, 4]. Furthermore, adiponectin is able to increase clear- 
Table 1. Conditions for RT-PCR quantification of mRNAs

\begin{tabular}{|c|c|c|c|c|c|}
\hline mRNA & Forward primer $\left(5^{\prime} \rightarrow 3^{\prime}\right)$ & Reverse primer $\left(5^{\prime} \rightarrow 3^{\prime}\right)$ & $\mathrm{T}_{\text {annealing }}\left[{ }^{\circ} \mathrm{C}\right]$ & No. of cycles & $\mathrm{MgCl}_{2}[\mathrm{mmol} / \mathrm{l}]$ \\
\hline PPAR $\gamma 1$ & agaacagatccagtggttgc & gccaacagcttctccttctc & 64 & 40 & 4 \\
\hline PGC-1 & tgtggaactctctggaactg & tgaggacttgctgagtggtg & 65 & 45 & 4 \\
\hline GLUT-4 & acagataggctccgaagatg & ccaagccactgagagatgat & 67 & 55 & 3 \\
\hline CD36 & ctaatgccagttggagacct & actgtgaagttgtcagcctc & 64 & 45 & 4 \\
\hline FATP-1 & caagcagtgtagccaacttc & cggaatccatagtacaccag & 68 & 60 & 3 \\
\hline Adiponectin & gtgatggcagagatggcac & agaggctgaccttcacatcc & 65 & 45 & 4 \\
\hline UCP-3 & atggacgcctacagaaccat & ctgggccaccatctttatca & 62 & 45 & 4 \\
\hline
\end{tabular}

ance of plasma free fatty acids, probably by induction of fatty acid transport protein-1 (FATP-1) gene expression in muscle $[5,6]$. Finally, anti-steatotic effects on liver and muscle due to increased fatty acid oxidation were shown and could be mediated by peroxisome proliferator-activated receptor (PPAR)- $\alpha[1,5]$.

Due to these beneficial effects of adiponectin, the regulation of its gene is currently being investigated. During in vitro studies, fat cell expression of adiponectin was shown to be repressed by factors known to be increased in insulin resistance, such as insulin [7], tumour necrosis factor- $\alpha[7,8]$, glucocorticoids $[7,9]$, and $\beta$-adrenergic agonists $[10,11]$. In contrast, the only stimulus for adiponectin gene expression in adipocytes known to date is the pharmacological activation of PPAR $\gamma$ by thiazolidinediones [12, 13].

The objective of this study was to examine whether adiponectin is able to induce in primary human myotubes genes of potential downstream targets, like FATP-1 and PPAR $\alpha$, as well as other genes related to insulin sensitivity in humans.

\section{Materials and methods}

Tissue sampling and cell culture. Primary human skeletal muscle cells were grown from satellite cells obtained from percutaneous needle biopsies carried out on the lateral portion of the quadriceps femoris (vastus lateralis) muscle [14]. The eight donors were normal weight healthy Caucasian subjects ( $2 \mathrm{men} /$ 6 women; age: $27 \pm 4$ years; BMI: $23.0 \pm 2.5 \mathrm{~kg} / \mathrm{m}^{2}$; mean \pm SD) and gave informed written consent prior to the biopsy. The experiments were carried out on subcultured (first pass) cells after growth to 80 to $90 \%$ confluence and subsequent differentiation to myotubes [14]. On day five of differentiation, the medium was replaced by the HEK293 supernatants and the myotubes were incubated therein for $48 \mathrm{~h}$ prior to RNA and protein analysis. Primary human skin fibroblasts were isolated from skin biopsies as formerly described [15]. The four donors who gave informed written consent prior to the biopsy were normal weight healthy Caucasians $(2 \mathrm{men} / 2$ women; age: $27 \pm$ 4 years; BMI: $22.1 \pm 3.1 \mathrm{~kg} / \mathrm{m}^{2}$; mean \pm SD). The fibroblasts were grown to subconfluence in DMEM supplemented with $2 \mathrm{mmol} / \mathrm{l}$ glutamine, $100 \mathrm{U} / \mathrm{ml}$ penicillin, $0.1 \mathrm{mg} / \mathrm{ml}$ streptomycin, $2.5 \mu \mathrm{g} / \mathrm{ml}$ amphotericin $\mathrm{B}$, and $10 \% \mathrm{FCS}$ and, there- after, incubated with HEK293 supernatants for 48 h. HepG2 hepatoma cells were cultured in minimum essential medium Eagle containing non-essential amino acids supplemented with $2 \mathrm{mmol} / \mathrm{l}$ glutamine, $1 \mathrm{mmol} / \mathrm{l}$ pyruvate, $100 \mathrm{U} / \mathrm{ml}$ penicillin, $0.1 \mathrm{mg} / \mathrm{ml}$ streptomycin, and $10 \%$ FCS. At subconfluence, the cells were incubated and assayed as described for fibroblasts and in vitro differentiated myotubes. The study was approved by the local ethics committee.

Production of HEK293 supernatants. Untransfected human embryonic kidney HEK293 cells and the HEK293 cell line stably transfected with a haemagglutinin (HA)-tagged human adiponectin cDNA were grown in DMEM/Ham's nutrient mixture F-12 (1:1) supplemented with $2 \mathrm{mmol} / \mathrm{l}$ glutamine, $100 \mathrm{U} / \mathrm{ml}$ penicillin, $0.1 \mathrm{mg} / \mathrm{ml}$ streptomycin, and $10 \% \mathrm{FCS}$. Having reached confluence, the cells were shifted to FCSreduced medium (as above but containing only $0.5 \%$ FCS). This medium was renewed every $24 \mathrm{~h}$. The medium conditioned during the first $24 \mathrm{~h}$ was discarded. The following 24-h conditioned media were cleared by centrifugation (700 g, $7 \mathrm{~min}$ ) and collected over a period of 18 days.

Immunoblotting of adiponectin. Qualitative and quantitative immunoblotting of adiponectin in HEK293 supernatants was done as described [16]. For detection of adiponectin in human myotube cultures, cells were washed and scraped off in PBS containing $1 \mathrm{mmol} / \mathrm{l}$ EDTA, $1 \mathrm{mmol} / \mathrm{l}$ phenylmethylsulfonylfluoride, $10 \mu \mathrm{g} / \mathrm{ml}$ aprotinin, $0.5 \mu \mathrm{g} / \mathrm{ml}$ leupeptin, and $0.7 \mu \mathrm{g} / \mathrm{ml}$ pepstatin. Thereafter, the cells were lysed on ice by sonication and the lysates were cleared by centrifugation. $100 \mu \mathrm{g}$ of total cell lysate, as determined by the Bradford method, were subjected to gel electrophoresis and immunoblotting.

$R T-P C R$. RNA was isolated with peqGOLD TriFast according to the manufacturer's instructions. Total RNA treated with RNase-free DNase I was transcribed into cDNA using AMV reverse transcriptase and the first strand cDNA kit from Roche Diagnostics. Total RNA from visceral adipose tissue served as standard for in vivo adiponectin mRNA expression. Quantitative PCR was carried out with SYBR Green I dye on a high speed thermal cycler with integrated microvolume fluorometer according to the instructions of the manufacturer. The PCR conditions are given in Table 1.

Quantification of adiponectin. Preparation of total cell lysates and determination of cellular protein were carried out as described. The adiponectin concentration was determined in $100 \mu \mathrm{l}$ aliquots in triplicate by radioimmunoassay. Adiponectin contents of myotube lysates are given as ng adiponectin/mg cell protein. 
Table 2. Influence of the adiponectin-containing HEK293 supernatant on expression of selected mRNAs in primary human myotubes

\begin{tabular}{|c|c|c|c|c|}
\hline mRNA & Supernatant & mRNA content $[\mathrm{AU}]$ & fold effect & $p$ \\
\hline \multirow[t]{2}{*}{ PPAR $\gamma 1$} & Control & $319.0 \pm 120.3$ & & \\
\hline & Adiponectin & $521.3 \pm 80.8$ & 1.6 & 0.16 \\
\hline \multirow[t]{2}{*}{ PGC-1 } & Control & $3,419.8 \pm 1,019.1$ & & \\
\hline & Adiponectin & $3,127.6 \pm 879.8$ & 0.9 & 0.9 \\
\hline \multirow[t]{2}{*}{ GLUT-1 } & Control & $206,911.9 \pm 60,177.5$ & & \\
\hline & Adiponectin & $216,475.6 \pm 61,592.2$ & 1.1 & 0.9 \\
\hline \multirow[t]{2}{*}{ GLUT-4 } & Control & $1.6 \pm 0.6$ & & \\
\hline & Adiponectin & $7.1 \pm 3.9$ & 4.4 & 0.3 \\
\hline \multirow[t]{2}{*}{ CD36 } & Control & $466.4 \pm 348.7$ & & \\
\hline & Adiponectin & $526.0 \pm 230.5$ & 1.1 & 0.4 \\
\hline \multirow[t]{2}{*}{ FATP-1 } & Control & $52.0 \pm 13.0$ & & \\
\hline & Adiponectin & $67.0 \pm 12.1$ & 1.3 & 0.4 \\
\hline \multirow[t]{2}{*}{ mFABP } & Control & $2,517.6 \pm 962.9$ & & \\
\hline & Adiponectin & $2,883.4 \pm 846.3$ & 1.2 & 0.7 \\
\hline \multirow[t]{2}{*}{ PPAR $\alpha$} & Control & $1332.8 \pm 167.9$ & & \\
\hline & Adiponectin & $1362.6 \pm 117.3$ & 1.0 & 1.0 \\
\hline \multirow[t]{2}{*}{ Adiponectin } & Control & $2.5 \pm 0.9$ & & \\
\hline & Adiponectin & $226.5 \pm 41.8$ & 90.7 & $<0.001$ \\
\hline \multirow[t]{2}{*}{ UCP-3 } & Control & $35.8 \pm 7.9$ & & \\
\hline & Adiponectin & $38.6 \pm 12.1$ & 1.1 & 0.8 \\
\hline
\end{tabular}

mRNA contents were determined in myotube cultures from eight donors $(n=8)$. RT-PCR quantification was carried out in triplicate. Data are given as means \pm S.E.M. (AU $=$ arbitrary units). $p$ values were determined by Mann-Whitney rank sum test

Statistical analysis. Data were analysed by Mann-Whitney rank sum test. A $p$ value of less than 0.05 was considered statistically significant.

Materials. All cell culture media, supplements, and reagents were purchased from Gibco BRL (Eggenstein, Germany). HEK293 cells stably transfected with the HA-tagged human adiponectin cDNA was a generous gift from Prof. Dr. med. G. Löffler (Institute for Biochemistry, Genetics, and Microbiology, University of Regensburg, Germany). The human adiponectin radioimmunoassay was from Linco Research (St. Charles, Mo., USA). Reagents for cDNA synthesis as well as the high speed thermal cycler with integrated microvolume fluorometer were purchased from Roche Diagnostics (Mannheim, Germany). The peqGOLD TriFast RNA isolation reagent was from Peqlab (Erlangen, Germany). PCR primers were obtained from Invitrogen (Karlsruhe, Germany).

\section{Results}

Adiponectin content of HEK293 supernatants. The control supernatant of untransfected and the supernatant of HEK293 cells stably transfected with the HAtagged human adiponectin cDNA were subjected to Western blotting. Adiponectin was not detectable in the control supernatant of wild-type HEK293 cells by this method. By contrast, the HEK293 adiponectin transfectant produced a supernatant enriched with human recombinant adiponectin-HA (Fig. 1). In this supernatant, an adiponectin concentration of $1.05 \mu \mathrm{g} / \mathrm{ml}$ was determined by the quantitative immunoblotting method.

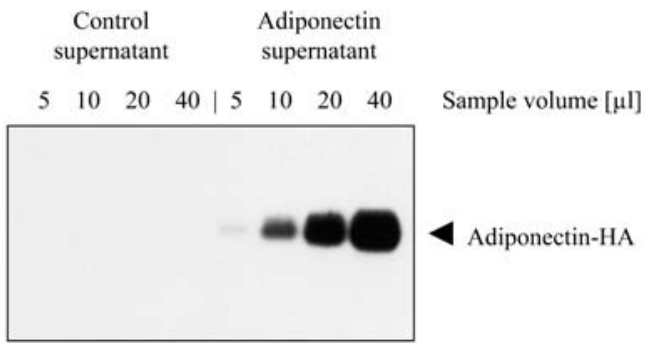

Fig. 1. Adiponectin content of HEK293 supernatants. 5, 10, 20 , and $40 \mu \mathrm{l}$ of supernatant were subjected to immunoblotting as described in Materials and Methods (Adiponectin-HA = HA-tagged human recombinant adiponectin)

Adiponectin supernatant-induced changes in myotube gene expression. To investigate whether the expression of selected genes involved in muscle glucose and fatty acid metabolism as well as energy homeostasis is specifically altered by adiponectin, we treated in vitro differentiated human myotubes from eight different donors with the above mentioned supernatants. During the 48-h incubation period, both supernatants affected neither morphology nor viability of the myotube cultures. The expression of PPAR $\gamma 1$, PPAR $\gamma$ coactivator 1 (PGC-1), GLUT-1, GLUT-4, CD36/fatty acid transporter (FAT), FATP-1, muscle fatty acid binding protein (mFABP), PPAR $\alpha$, and uncoupling protein 3 (UCP-3) did not show significant differences when cells were treated with HEK293 adiponectin supernatant versus control supernatant (Table 2).

We also tested whether adiponectin modulates expression of its own gene in muscle cells. Adiponectin 


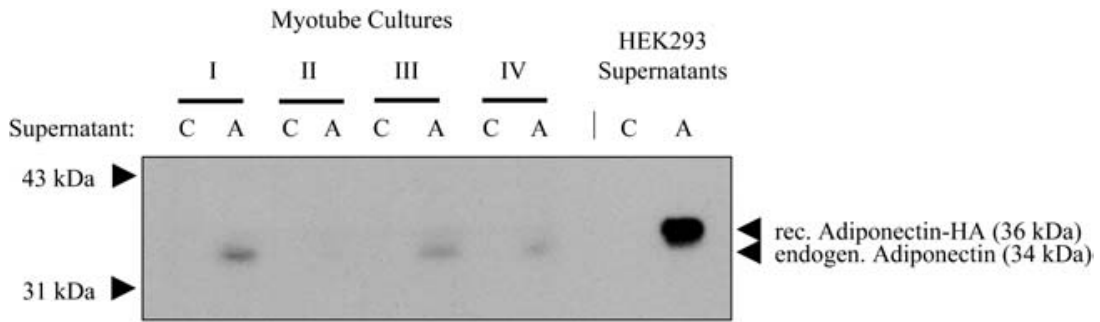

Fig. 2. Adiponectin expression in human myotube cultures. Cells from four donors (I-IV) were treated for $48 \mathrm{~h}$ with HEK293 control (C) and adiponectin (A) supernatant. To check for the presence of recombinant (rec.) HA-tagged adiponectin, $20 \mu \mathrm{l}$ of control and adiponectin supernatant were blotted in parallel
A

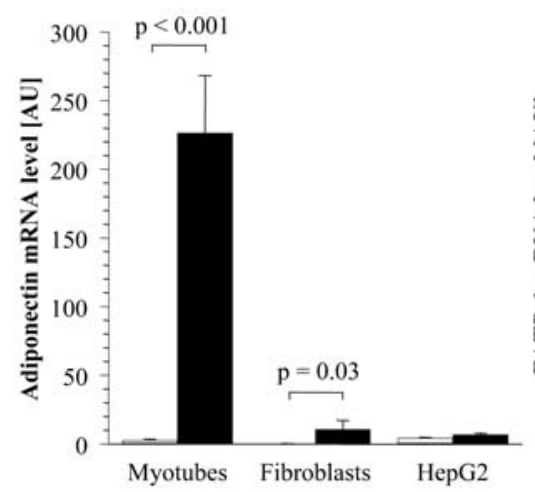

B

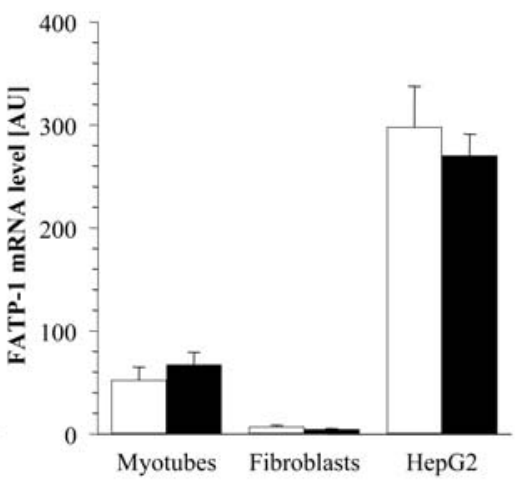

$\square$ Control supernatant
C

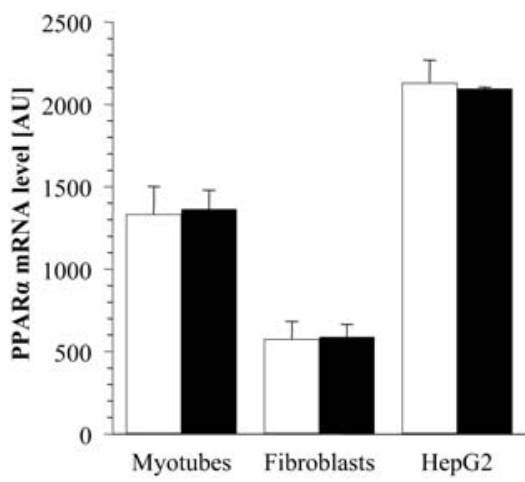

Fig. 3A-C. Expression of adiponectin (A), FATP-1 (B), and PPAR $\alpha(\mathbf{C})$ mRNA in human myotubes, skin fibroblasts, and HepG2 cells. Cells were treated for 48 h with HEK293 control (white bars) and adiponectin (black bars) supernatant. mRNAs were quantified by RT-PCR in triplicates. Data are derived from eight (myotubes), four (fibroblasts), and three (HepG2) independent experiments. Data are given as means \pm S.E.M. (AU $=$ arbitrary units). $p$ values were determined by MannWhitney rank sum test

mRNA expression of in vitro differentiated human myotubes incubated with the control supernatant ranged at the detection limit. However, the adiponectin supernatant induced a 90-fold increase on average in adiponectin mRNA in these myotubes (Table 2). This effect was consistently seen in myotube cultures from all eight donors. To exclude that this signal originates from the adiponectin supernatant, we carried out additional RT-PCR with a reverse primer directed against the HA-tag. Whereas the HEK293 adiponectin transfectant produced a signal corresponding to HAtagged recombinant adiponectin, human myotubes treated with adiponectin supernatant did not $(n=4$, data not shown). The amount of myotube adiponectin mRNA after exposure to the adiponectin supernatant reached $0.25 \pm 0.04 \%$ of the adiponectin mRNA con- tent of visceral adipose tissue. To verify that human myotubes indeed express adiponectin, we analysed total myotube lysates from four donors by immunoblotting. The adiponectin supernatant induced amounts of endogenous adiponectin protein that ranged at the detection limit of this method but were visible in myotube cultures from three donors (I, III, and IV) (Fig. 2). By radioimmunoassay, adiponectin protein expression was found to be on average increased 8.3-fold in myotubes exposed to adiponectin supernatant compared with control supernatant $(29.7 \pm 6.7 \mathrm{ng} / \mathrm{mg}$ vs $3.5 \pm 0.6 \mathrm{ng} / \mathrm{mg}, n=4, p<0.05)$.

Adiponectin, FATP-1, and PPAR $\alpha$ mRNA expression in skin fibroblasts and HepG2 cells. The adiponectinenriched HEK293 supernatant increased adiponectin mRNA expression in human skin fibroblasts and HepG2 cells as well (Fig. 3A). In contrast to the situation in myotubes, however, the amount of adiponectin mRNA in fibroblasts and hepatoma cells was still at the detection limit, even after incubation with the adiponectin supernatant. Furthermore, in fibroblasts and HepG2 cells the mRNA expression of adiponectin's hypothetical downstream targets FATP-1 and PPAR $\alpha$ was unchanged, as was seen in human myotubes (Fig. 3B,C). 


\section{Discussion}

In mice, it was shown that adiponectin has insulin-sensitizing properties by reduction of free fatty acids in plasma $[5,6]$, elevation of skeletal muscle fatty acid oxidation $[1,5]$, and enhancement of insulin's suppressive action on hepatic gluconeogenesis $[3,4]$. With regard to its lipid-lowering function, it was speculated that adiponectin increases the uptake of free fatty acids into muscle via FATP-1 [6] and fatty acid oxidation by PPAR $\alpha$-dependent induction of fatty acid-oxidizing enzymes [1]. Therefore, we examined here the expression of its hypothetical downstream signalling elements, i.e. FATP-1 and PPAR $\alpha$, in human myotubes, skin fibroblasts, and HepG2 cells after treatment with an adiponectin-containing HEK293 supernatant. In contrast to the in vivo findings in adiponectin-knockout [6] and lipoatrophic mice [1], neither FATP-1 nor PPAR $\alpha$ were induced at the mRNA level by adiponectin in the human cell types tested. This raises the possibility that adiponectin exerts its effects on skeletal muscle expression of FATP-1 and PPAR $\alpha$ indirectly. Alternatively, differences in the signalling mechanisms of adiponectin between mice and humans might underlie this discrepancy.

Furthermore, we studied the effect of the adiponectin-enriched supernatant on eight other genes implicated in glucose and lipid metabolism in human myotubes. This treatment selectively upregulated the expression of the adiponectin gene, whereas the other genes were unaffected. This opens the possibility that in muscle cells adiponectin can initiate an autocrine loop allowing continuous cellular stimulation by adiponectin which, in turn, might be a prerequisite for the maintainance of muscle cell insulin sensitivity. Expression of adiponectin mRNA and protein in myotubes was most probably not due to contamination of the myotube cultures with adipocytes since (i) parallel cultures of comparable purity did not show adiponectin expression after exposure to the control supernatant, and (ii) myotubes incubated with thiazolidinediones, potent adipogenic agents and strong inducers of adiponectin gene expression, did not show elevated adiponectin expression. Therefore, it is suggested that adiponectin expression can be induced in non-adipose cells. The increase in adiponectin mRNA could not be attributed to contamination with fibroblasts either because human skin fibroblasts exhibited at least 20-fold lower adiponectin mRNA expression than myotube cultures after incubation with the adiponectin supernatant. Therefore, we conclude that adiponectin expression is specifically inducible in muscle cells. The maximum adiponectin mRNA content reached in myotubes is lower than that obtained in visceral adipose tissue. However, the local efficacy might still be high since it is directly acting on the myotubes. Furthermore, the amounts of adiponectin mRNA reached by myotubes are well in the range of in vitro cell culture models since similar amounts were obtained with 3T3-L1 adipocytes (data not shown). In conclusion, we show here that adiponectin gene expression is not necessarily restricted to adipocytes but is also inducible in skeletal muscle cells.

Acknowledgements. We thank Dr. A. Kappes and Prof. Dr. med. G. Löffler for their generous support with tools and advice. Dr. Stumvoll is supported by a Heisenberg grant from the Deutsche Forschungsgemeinschaft.

\section{References}

1. Yamauchi T, Kamon J, Waki $H$ et al. (2001) The fatderived hormone adiponectin reverses insulin resistance associated with both lipoatrophy and obesity. Nat Med 7:941-946

2. Berg AH, Combs TP, Scherer PE (2002) Acrp30/adiponectin: an adipokine regulating glucose and lipid metabolism. Trends Endocrinol Metab 13:84-89

3. Berg AH, Combs TP, Du X et al. (2001) The adipocytesecreted protein Acrp30 enhances hepatic insulin action. Nat Med 7:947-952

4. Combs TP, Berg AH, Obici S et al. (2001) Endogenous glucose production is inhibited by the adipose-derived protein acrp30. J Clin Invest 108:1875-1881

5. Fruebis J, Tsao TS, Javorschi S et al. (2001) Proteolytic cleavage product of $30-\mathrm{kDa}$ adipocyte complement-related protein increases fatty acid oxidaton in muscle and causes weight loss in mice. Proc Natl Acad Sci USA 98:2005-2010

6. Maeda N, Shimomura I, Kishida K et al. (2002) Dietinduced insulin resistance in mice lacking adiponectin/ Acrp30. Nat Med 8:731-737

7. Fasshauer M, Klein J, Neumann S et al. (2002) Hormonal regulation of adiponectin gene expression in 3T3-L1 adipocytes. Biochem Biophys Res Commun 290:1084-1089

8. Kappes A, Löffler G (2000) Influences of ionomycin, dibutyryl-cycloAMP and tumour necrosis factor-alpha on intracellular amount and secretion of apM1 in differentiating primary human preadipocytes. Horm Metab Res 32:548-554

9. Halleux CM, Takahashi M, Delporte ML et al. (2001) Secretion of adiponectin and regulation of apM1 gene expression in human visceral adipose tissue. Biochem Biophys Res Commun 288:1102-1107

10. Fasshauer M, Klein J, Neumann S et al. (2001) Adiponectin gene expression is inhibited by $\beta$-adrenergic stimulation via protein kinase $\mathrm{A}$ in $3 \mathrm{~T} 3-\mathrm{L} 1$ adipocytes. FEBS Lett 507:142-146

11. Delporte ML, Funahashi T, Takahashi M et al. (2002) Preand post-translational negative effect of $\beta$-adrenoceptor agonists on adiponectin secretion: in vitro and in vivo studies. Biochem J: electronic publication ahead of print

12. Maeda N, Takahashi M, Funahashi T et al. (2001) PPAR $\gamma$ ligands increase expression and plasma concentrations of adiponectin, an adipose-derived protein. Diabetes 50:2094-2099

13. Combs TP, Wagner JA, Berger J et al. (2002) Induction of adipocyte complement-related protein of 30 kilodaltons by PPAR $\gamma$ agonists: a potential mechanism of insulin sensitization. Endocrinology 143:998-1007

14. Krützfeldt J, Kausch C, Volk A et al. (2000) Insulin signaling and action in cultured skeletal muscle cells from lean healthy humans with high and low insulin sensitivity. Diabetes 49:992-998

15. Sly WS, Grubb J (1979) Protocol for skin biopsy and fibroblast isolation. Methods Enzymol 58:444-450

16. Staiger H, Tschritter O, Kausch C et al. (2002) Human serum adiponectin levels are not under short-term negative control by free fatty acids in vivo. Horm Metab Res 34: 601-603 